\title{
Retraction Note: Management of offshore oil pollution and logistics transportation based on decision tree
}

\author{
Li Zhang ${ }^{1}$
}

Published online: 6 December 2021

C) Saudi Society for Geosciences 2021

Retraction Note: Arabian Journal of Geosciences (2021) 14: 1655 https://doi.org/10.1007/s12517-021-07903-9

The Editor-in-Chief and the Publisher have retracted this article because the content of this article is nonsensical. The peer review process was not carried out in accordance with the Publisher's peer review policy. The author has not responded to correspondence regarding this retraction.

The original article can be found online at https://doi.org/10.1007/ s12517-021-07903-9

Li Zhang

zhlyzl2021@163.com

1 School of International Economics, Shaanxi Institute of International Trade and Commerce, Xianyang 712046, Shaanxi, China 